\title{
Modeling the effects of pollutant emissions from large industrial complexes on benzene, toluene, and xylene concentrations in urban areas
}

\author{
Jin-Hee Bang ${ }^{1}$, Inbo $\mathrm{Oh}^{1}$, Soontae $\mathrm{Kim}^{2}$, Seunghee $\mathrm{You}^{2}$, Yangho Kim ${ }^{1,3}$, Ho-Jang Kwon ${ }^{4}$, \\ Geun-Bae Kim ${ }^{5}$ \\ ${ }^{1}$ Environmental Health Center, University of Ulsan College of Medicine, Ulsan, Korea; ${ }^{2}$ Department of Environmental Safety \\ Engineering, Ajou University, Suwon, Korea; ${ }^{3}$ Department of Occupational and Environmental Medicine, University of Ulsan \\ College of Medicine, Ulsan, Korea; ${ }^{4}$ Department of Preventive Medicine, Dankook University College of Medicine, Cheonan, \\ Korea; ${ }^{5}$ Environmental Health Research Division, National Institute of Environmental Research, Incheon, Korea
}

\begin{abstract}
This study utilized the Community Multiscale Air Quality model to simulate the spatial distribution of benzene, toluene, and xylene (BTX) concentrations from large national industrial complexes (IC) located in the Ulsan metropolitan region (UMR). Through controlling pollutant emissions from major IC, this study performed a quantitative analysis of the influence of pollutant emissions on BTX concentrations in surrounding urban areas. The results showed that approximately $40 \%$ of the annual average BTX concentrations in nearby urban grids were directly influenced by pollutant emissions from the IC. Seasonal modeling results indicated that average BTX concentrations were high around petrochemical complexes, with higher concentrations in the surrounding urban areas during the summer (July). All three of the BTX pollutants showed similar seasonal differences. Daily contributions differed significantly throughout the modeling period, with some values reaching a maximum of $80 \%$ during July. Overall, when urban areas were located downwind of the IC, contributions rose. Moreover, this study compared the differences in BTX contributions at each measurement point within the IC and urban areas, which showed that the influence of the IC emissions decreased significantly with distance. The spatial distribution and direct influence of the IC on BTX concentrations in the UMR identified through this study could be used to provide input data in environmental epidemiological studies.
\end{abstract}

Keywords: Community Multiscale Air Quality, Benzene, Toluene, Xylene, Ulsan, Industrial complex

\author{
Correspondence: : Inbo Oh \\ Environmental Health Center, University of \\ Ulsan College of Medicine, 877 \\ Bangeojinsunhwando-ro, Dong-gu, Ulsan \\ 44033, Korea \\ E-mail: oinbo@ulsan.ac.kr \\ Received: July 18, 2017 \\ Accepted: November 20, 2017 \\ Published: November 20, 2017 \\ This article is available from: http://e-eht.org/
}

\section{INTRODUCTION}

Ulsan is a major industrial city in Korea and is the location of large-scale national industrial complexes (IC), including petrochemical facilities. Air pollution has been the most important environmental issue of the region in past decades. In particular, hazardous air pollutants (HAPs) related to emissions from IC represent an important aspect of atmospheric environment management in the Ulsan metropolitan region (UMR), presenting a significant need for air pollutant monitoring and analysis of pollutant spatial distribution.

HAPs can be transported through the atmosphere in gas or aerosol forms, spreading out widely over days or weeks [1]; these pollutants are hazardous to human health and are precursors to ozone $\left(\mathrm{O}_{3}\right)$, thus contribute to urban photochemical smog [2-4]. Among such pollutants, benzene, toluene, and xy- 
lene (BTX) are representative HAPs in the UMR, comprising almost $70 \%$ of the chemical emissions in the region [5]. BTX is often used as an indicator of volatile organic compounds (VOCs) [6], which show high concentrations around petrochemical factories due to petroleum manufacture [7]. Of the 32 nationwide national HAPs monitoring sites (NHAMS) operated by the Ministry of the Environment, BTX concentrations at the Yeocheon site, within the Ulsan petrochemical complex, is the highest; in the case of benzene, its concentration exceeded the annual air quality standard ( 1.5 parts per billion [ppb]) between 2012 to 2015 [8]. Moreover, given the location of this site in the UMR, high BTX concentrations are likely in adjacent urban areas. This can be inferred from the numerical modeling study by $\mathrm{Oh}$ et al. [9], conducted in the same region; this study indicates a significant rise in pollutant concentrations downwind of the IC depending on the characteristic seasonal wind conditions.

The quantification of BTX concentrations contributed by IC, as well as exposure levels experienced by nearby residents, are important aspects in the management of environmental HAPs concentrations and in environmental epidemiological studies. Currently, there are only two NHAMS in the UMR, which is wholly insufficient to understand regional spatial BTX distributions and the exposure level to residents. A few previous studies $[10,11]$ have sought to measure local BTX levels, with measurements restricted to specific areas and time periods; however, these studies provide only limited understanding of the spatial BTX distribution in the UMR. To obtain high-resolution BTX concentration information and to identify the influence of air pollutant emissions from the IC, it is important to apply an appropriate numerical model using accurate pollutant emission data, as well as a modeling method that can evaluate the influence of the air pollutant emissions from the IC.

This study conducted high-resolution air quality modeling on a seasonal basis over the UMR and researched average spatial distribution of BTX concentrations in both the IC and nearby areas. Moreover, this study quantitatively analyzed the contribution of industrial activity to the change in BTX concentrations in nearby urban areas by controlling pollutant emissions from major IC.

\section{METHODS}

\section{Target Area}

Ulsan is a metropolis with a population of 1.2 million (as of December 2016), surrounded by high mountains more than $1000 \mathrm{~m}$ in altitude, and a complex shoreline to the southeast. The urban environment is characterized by major national IC of the shipbuilding, petrochemical, and automotive industries.
These are located in the hilly coastal areas of the ports of Ulsan, Onsan, and Bangeojin, connected to the Ulsan Bay [9]. Notably, the Ulsan National Industrial Complex and Onsan National Industrial Complex have the highest chemical emissions among the national IC of Korea (7 $236245 \mathrm{~kg} \mathrm{yr}^{-1}$, as of 2014) [5]. Residential areas are mainly located near the IC. Fourteen air quality monitoring sites (AQMS) are located within the region, which provide sufficient coverage to verify the model results.

The 30-year (1981-2010) temperature and rainfall averages in Ulsan are $14.1^{\circ} \mathrm{C}$ and $1277 \mathrm{~mm}$, respectively, and display mild climate characteristics with high rainfall in the summer [12]. Spatially, the high temperatures are pronounced at the urban cores and the IC, with large differences between the coastal and rural areas in the winter (maximum $2.6^{\circ} \mathrm{C}$, November) [13]. North-northwesterly winds are pronounced during the year, whilst April and July are characterized by weak winds from varying directions. In terms of air pollution, the influence of the large-scale IC leads to the highest sulfur dioxide $\left(\mathrm{SO}_{2}\right)$ concentrations among all metropolitan cities in Korea, with areas near the IC having high concentrations of VOC [14].

\section{Modeling Method}

This study utilized the Community Multiscale Air Quality (CMAQ) model (version 5.0.1; https://www.epa.gov/cmaq) for BTX simulations. The CMAQmodel is a $3 \mathrm{D}$ photochemical dispersion model developed by the US Environmental Protection Agency (EPA), which can model major gaseous/particulate air pollutants, such as $\mathrm{O}_{3}$ and fine particulates, and enables simultaneous multiscale simulations $[15,16]$. A total of 5 modeling domains were used (Figure 1A); the fine domain (D5, $61 \times 55$ grid) was a high-resolution area with a $1-\mathrm{km}$ grid spacing that included the UMR and surrounding regions; this was the main analysis area. The model domains of the Weather Research and Forecasting (WRF) model (version 3.6.1; https:// www.mmm.ucar.edu/weather-research-and-forecasting-model), which were performed to produce the meteorological input to the CMAQ model, contained 6 more grids towards the south-north/east-west than CMAQ grids. The initial and boundary conditions entered in the WRF model were final analyses and sea surface temperature data provided by the $\mathrm{Na}$ tional Centers for Environmental Prediction (NCEP) and National Center for Atmospheric Research (NCAR); the physical parameterization methods and the options used were the same as those applied in the study by $\mathrm{Oh}$ et al. [13].

To process the gridded emissions for the CMAQ model, this study utilized the Sparse Matrix Operator Kernel Emissions (SMOKE) modeling system (version 3.1; https://www.cmascenter.org/smoke/) developed by the EPA [17]. The latest 

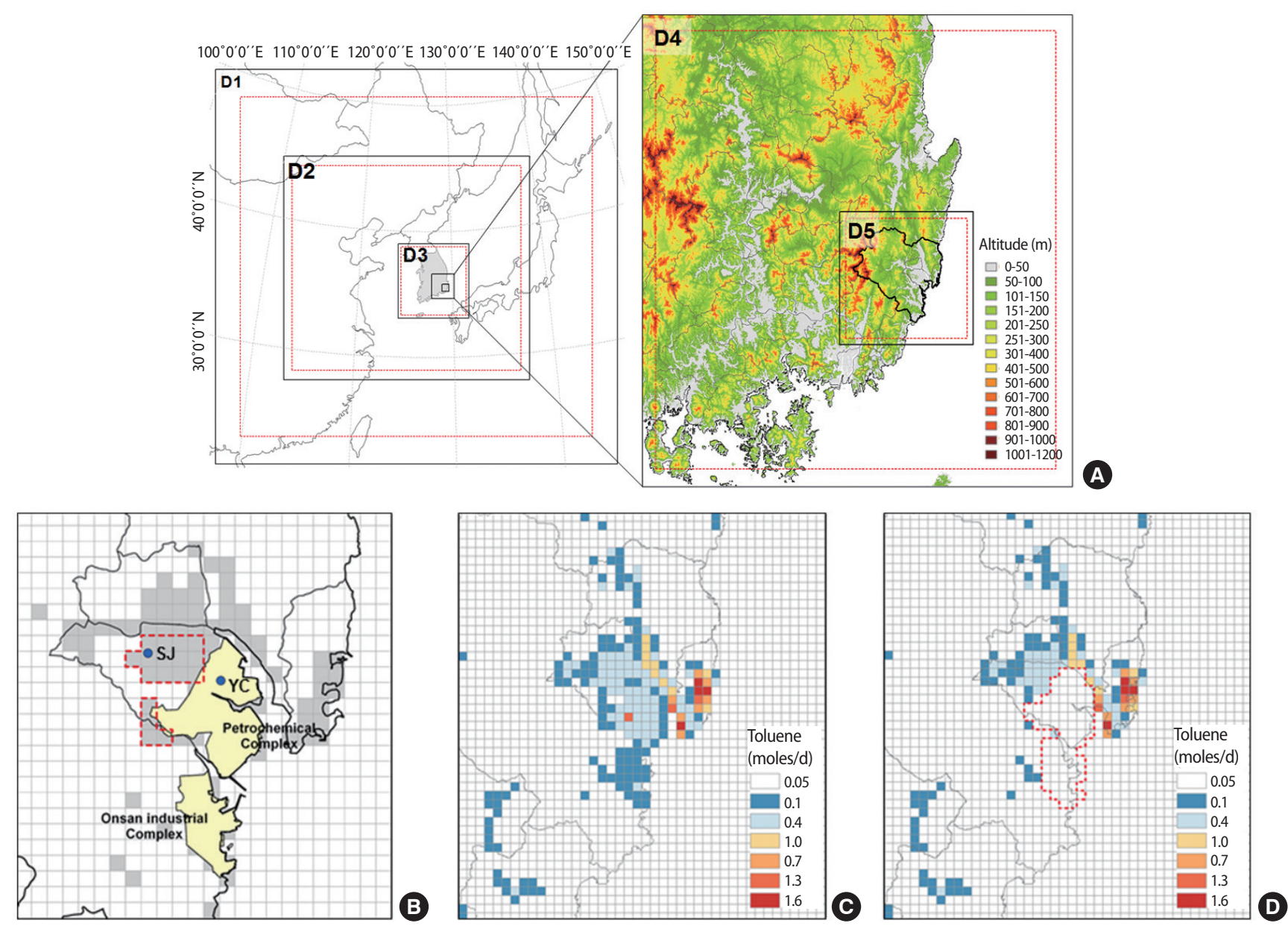

Figure 1. (A) WRF (black rectangle) and CMAQ (red-dashed rectangle) modeling domains and terrain in the UMR and its surroundings. (B) Urban residential areas (gray shaded areas), industrial complexes (yellow shaded areas), and measurement sites for hazardous air pollutants (blue dots). Distribution of all toluene emissions (C) with or (D) without emissions from the selected industrial complexes. WRF, weather research and forecasting; CMAQ, Community Multiscale Air Quality; UMR, Ulsan metropolitan region.

profile data, improved with US EPA data, was applied for the time distribution of emissions for SMOKE [18], and the Multiscale Integrated Modeling System (version 4.2) [19] spatial allocator was utilized to produce the surrogate coefficient for spatial allocation. The Carbon Bond 05 Toxic (CB05T) was used for the chemical mechanism for chemical species distribution. CB05T is an expansion mechanism of CB05 [20], which individually considers benzene, methane, and unreactive VOCs, as well as adding the distribution coefficients of various toxic compounds (increasing the number of VOC species from 14 to 21), and allows for appropriate reflection of chemical reactions of HAPs. Moreover, vertical distribution of emissions was conducted for point sources based on meteorological data.

The options applied to the chemical transport model of CMAQ are shown in Table S1, and are equivalent to the studies on the optimization method for improving the accuracy of air quality modeling conducted by National Institute of Environmental Research (NIER) [21]. CMAQ modeling was conducted in Janu- ary, April, July, and October 2014, and thus located in the middle of each season; the modeling of each month included 2 days of spin-up time to reduce the uncertainty of initial conditions.

\section{Emission Calculation}

Emission input data for the CMAQ modeling combined biogenic and anthropogenic emissions. The biogenic emissions were calculated by inputting vegetation data (leaf area index, plant functional type, emission factors, etc.) and meteorological data produced by Meteorology-Chemistry Interface Processor to the Model of Emissions of Gases and Aerosols from Nature version 2.04 [22].

Anthropogenic emissions were calculated by the SMOKE using the emission list in the Clean Air Policy Support System (CAPSS) 2013 of NIER, applied to the Model Inter-comparison Study for Asia (MICS-Asia) 2010 [23], which comprises residential, industrial, generation, transportation, and agricultural aspects. On the $81 \mathrm{~km}$ and $27 \mathrm{~km}$ grid domains, the emissions 
from MICS-Asia were utilized; the $9 \mathrm{~km}$ grid domain, including the Korean Peninsula, utilized the CAPSS and MICS-Asia emissions on South Korea and North Korea, respectively. On the 3 $\mathrm{km}$ and $1 \mathrm{~km}$ grid domain, including the UMR, CAPSS emissions were used. As it was difficult to utilize the VOC chemical species distribution coefficient specific to the Korean emission inventory on the model chemical type classifications for the VOCs emissions, profiles provided by the US EPA were utilized.

\section{Model Evaluation and Analysis Methods}

The quantitative evaluation of the meteorological inputs for CMAQ modeling was conducted using major statistical indices [9], which compare the surface temperature and wind speed values calculated by WRF with observed data from 9 monitoring sites in the UMR.

The verification of BTX modeling was performed for two HAPs monitoring sites within Ulsan (Sinjeong [SJ] and Yeocheon [YC] in Figure 1), by monitoring concentrations once a month (over a 24-hour period). As the information on the BTX measurement dates were not provided for the operation guidelines for NHAMS [24], this study compared the monthly average model concentrations with the concentrations measured once a month. Moreover, in evaluating the CMAQ modeling performance, the modeled hourly-mean concentrations of particulate matter with an aerodynamic diameter $<10 \mu \mathrm{m}\left(\mathrm{PM}_{10}\right)$, nitrogen dioxide $\left(\mathrm{NO}_{2}\right)$, and $\mathrm{O}_{3}$ were compared with measurements obtained from 14 AQMS in the UMR, using statistical indices (mean, Pearson correlation coefficient: r, normalized mean bias, normalized mean error, root mean square error, and index of agreement $[\mathrm{IOA}]$ ).

To determine the influence of the IC emissions on BTX concentrations, the spatio-temporal changes in BTX concentrations were investigated by comparing the model result obtained when considering all pollutant emissions within the domains (simulation A) with the model result gained by removing the pollutant emissions of major IC from all emissions in the domains (simulation B) (Figure 1C and 1D). In addition, to determine the quantitative contributions of pollutant emission from the IC, the average grid concentrations of the selected urban areas near IC (17 cells within the red-dotted shape in Figure 1B) and grid values at the two NHAM sites (YC and SJ) were analyzed.

\section{RESULTS}

\section{Model Evaluation}

This study confirmed that the changes and distributions of observed mereological values were closely reproduced by the WRF model for all seasons. Taking mean bias error values as an example, temperature showed a range of -0.25 to 0.45 , and wind speed range of 0.14 to 0.59 , indicating the reliability of the model results with correlation values (r) close to 1 . Particularly, IOA values for temperature ( 0.95 to 0.96 : temperature at $2 \mathrm{~m}$ above ground; 0.82 to 0.89 : wind speed at $10 \mathrm{~m}$ above ground) was found to be very high.

To investigate the overall reproducibility of the CMAQ simulation, the statistical evaluation for $\mathrm{PM}_{10}, \mathrm{NO}_{2}$, and $\mathrm{O}_{3}$ were conducted (Table S2). For $\mathrm{PM}_{10}$, statistics indicated an overall underestimation trend in the model. The correlation between the modeled and measured values were in the range of 0.43 to 0.65 , and the IOA values showed a level of agreement at the range of 0.50 to 0.68 . Compared with the modeling results of NIER's atmospheric quality modeling accuracy improvement study [21], the degree of correlation was similar. The modeling accuracy of April (spring) was comparatively lower-this was interpreted as due to the large uncertainties associated with regional transport of fine particulate matter, such as the Asian dust. Conversely, both $\mathrm{NO}_{2}$ and $\mathrm{O}_{3}$ had high correlations with measured values. In particular, IOA values were high in both $\mathrm{NO}_{2}$ and $\mathrm{O}_{3}$, with respective ranges of 0.72 to 0.80 and 0.74 to 0.81 . Moreover, time-series analysis indicated that the model had closely reproduced the measured concentration levels and trends of change (data not shown).

Figure 2 shows the distribution of monthly-mean BTX concentrations measured at the YC and SJ sites, and the model values of the grids where the sites were located. Firstly, while there was a difference between the measured and modeled values for the YC site located within the IC, these values are higher than the measurements at the SJ site located in an urban residential area. The measured values at the $\mathrm{YC}$ site were higher than the modeling values, with significant differences for xylene. Conversely, the modeled BXT concentrations at the SJ site were higher or equal in distribution compared to the measured values.

\section{Horizontal Distribution of Benzene, Toluene, and Xylene Concentrations}

Figure 3 presents the horizontal distributions of modeled BTX concentrations in the UMR. The gridded averages of January, April, July, and October, and the annual average values show the overall high-level concentrations in the IC and surrounding regions as well as significant seasonal differences. For July, the BTX concentration tended to rise in the urban inlands; this could be attributed to the effects of IC emissions, linked with southerly winds, which are more frequent during this time. January had comparatively high BTX concentration levels (toluene in January: 0.8 to $8.7 \mathrm{ppb}$; July: 0.2 to $9.1 \mathrm{ppb}$ ), but there were no clear seasonal differences. This was similar to the seasonal 

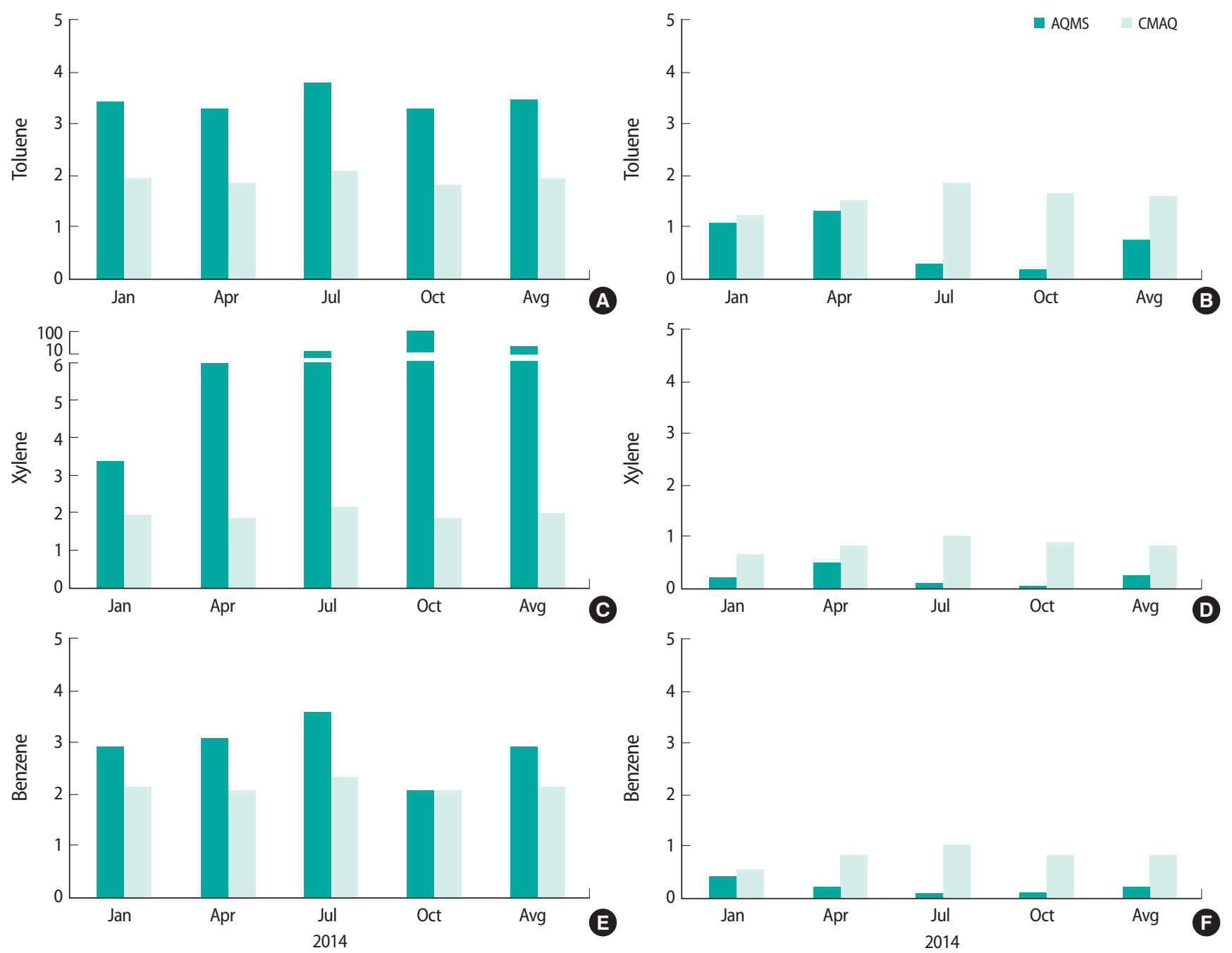

Figure 2. Comparison of measured and modeled BTX concentrations (unit: ppb). Measurements were obtained at two sites in YC (A, C, and E: industrial complex) and SJ (B, D, and F: urban residential) located in the Ulsan metropolitan region. BTX, benzene, toluene, and xylene; ppb, parts per billion; AQMS, air quality monitoring sites; CMAQ, Community Multiscale Air Quality; YC, Yeocheon; SJ, Sinjeong; Avg, average.

distribution trends of BTX concentrations at YC and SJ sites; the concentrations at each site tended to reflect local characteristics rather than seasonal ones $[25,26]$. There were some BTX concentrations on the sea near the coasts of Ulsan; this could be attributed to the pollutants emitted from ships and the IC, linked with regional or local winds.

\section{The Influence of Pollutant Emissions From Industrial Complexes}

Figure 4 shows the seasonal and annual average spatial distribution of BTX concentrations calculated by subtracting simulation $B$ from $A$. These values reflect the contribution of pollutant emissions from the IC; compared to the BTX distributions of simulation A, which consider the total emissions, it could be confirmed that the high-concentration range was restricted to the vicinities of the IC. Moreover, notwithstanding small differ- ences by pollutants, April and July showed higher concentrations under average wind conditions within the urban inland, indicating the influence of the IC.

To quantitatively evaluate the influence of the IC on the BTX concentrations in the IC and nearby urban areas, this study analyzed the emission-controlled simulation results at the selected urban areas (17 cells) and at each grid point containing the NHAM sites (YC, SJ) (Table 1). The contribution to urban BTX concentrations (the ratio of differences between simulation $\mathrm{A}$ and $\mathrm{B}$ on simulation $\mathrm{A}$ concentrations) yielded results of $36.6 \%$ for benzene, $39.5 \%$ for toluene, and $39.5 \%$ for xylene. All three compounds showed significant seasonal differences (the differences in January and April were more than 30\%), with the actual contributions largest in July (benzene, $50.8 \%$; toluene, $54.3 \%$; xylene, 55.4\%). Moreover, analyzing the individual contributions on the YC and SJ sites, the values of the YC site were 

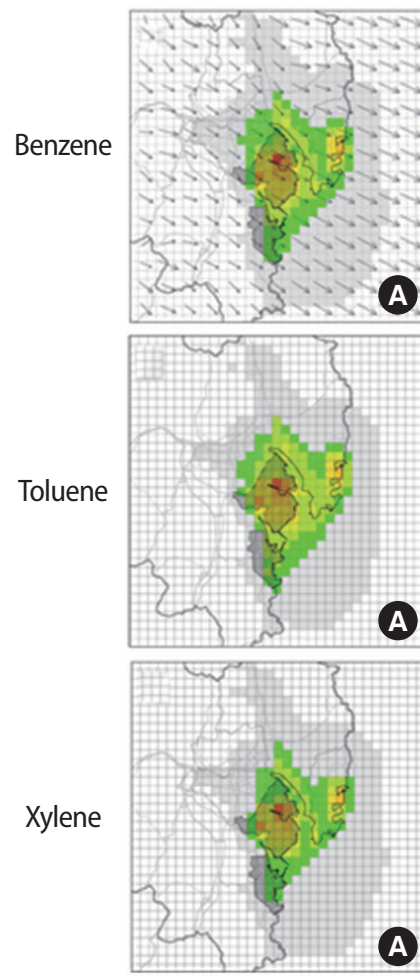

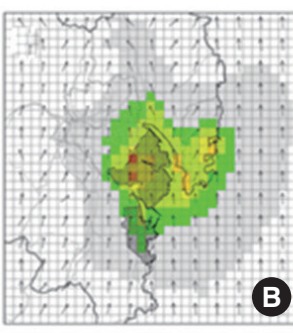

B
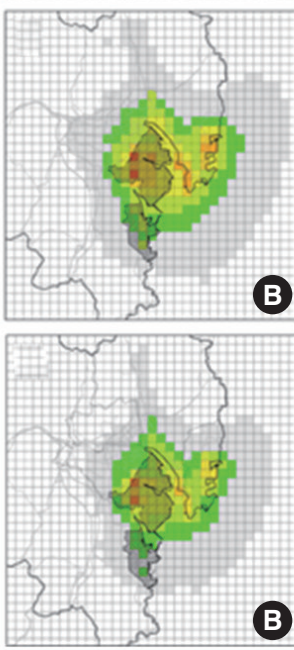
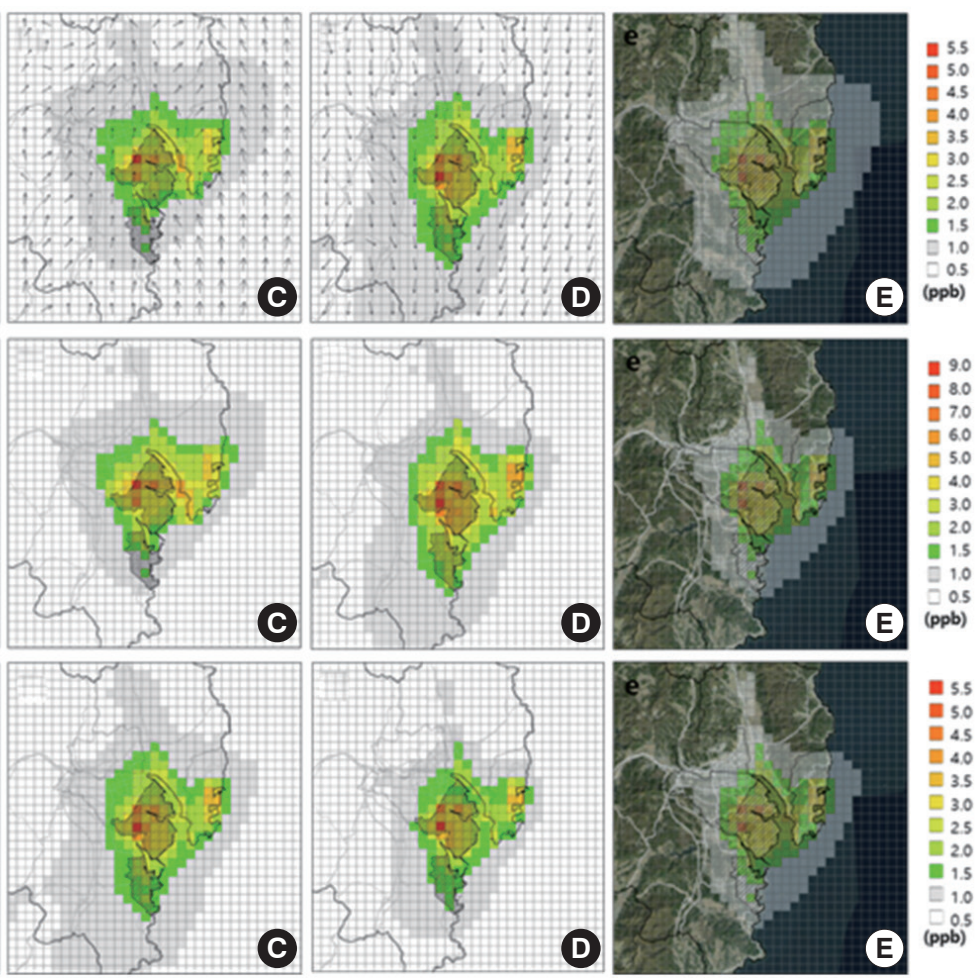

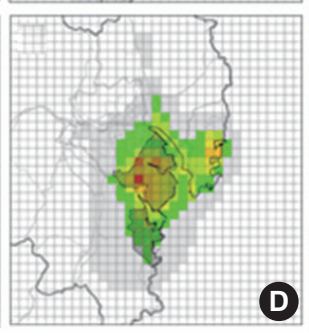

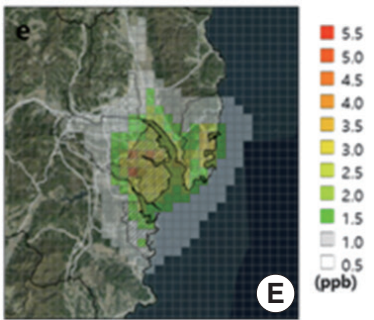

Figure 3. Horizontal distributions of the monthly mean simulated benzene, toluene and xylene (BTX) concentrations and wind vectors (A) January, (B) April, (C) July, (D) October, and (E) annual mean BTX concentrations and terrain image in the Ulsan metropolitan region. ppb, parts per billion.
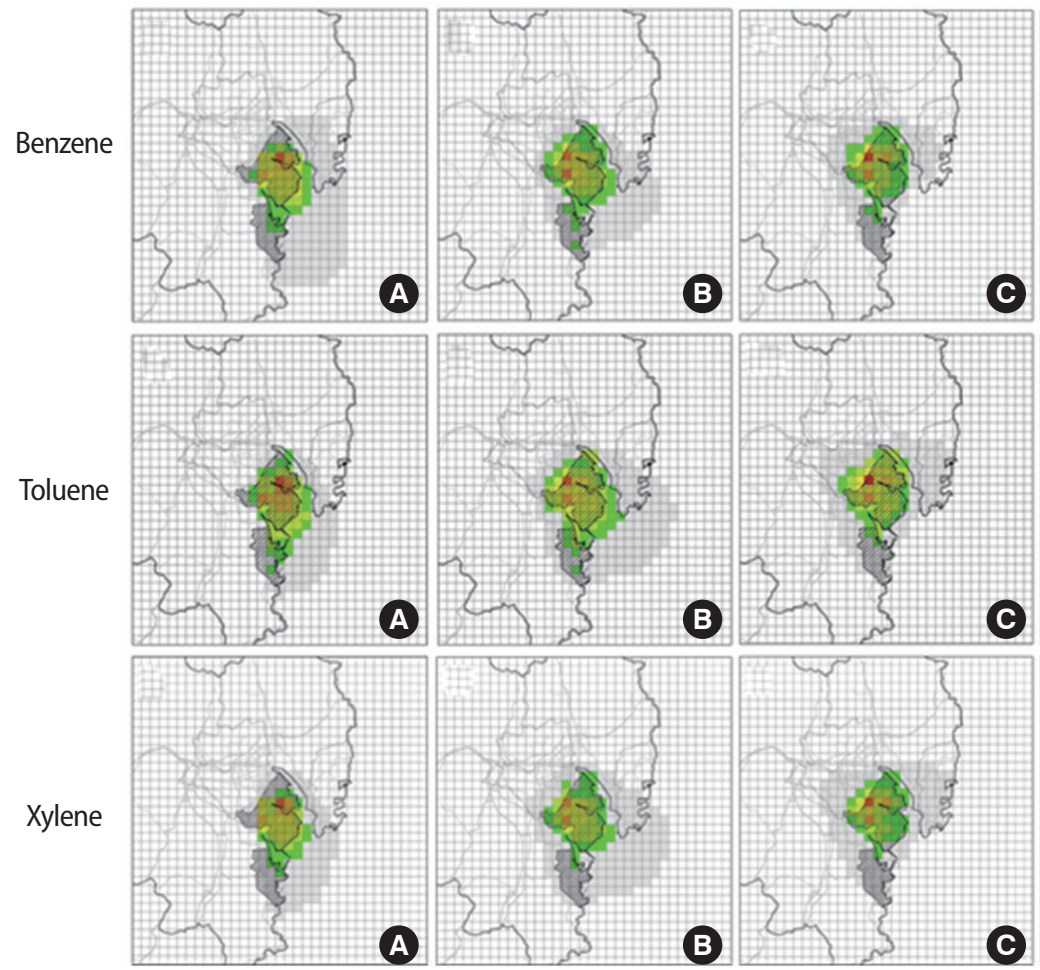
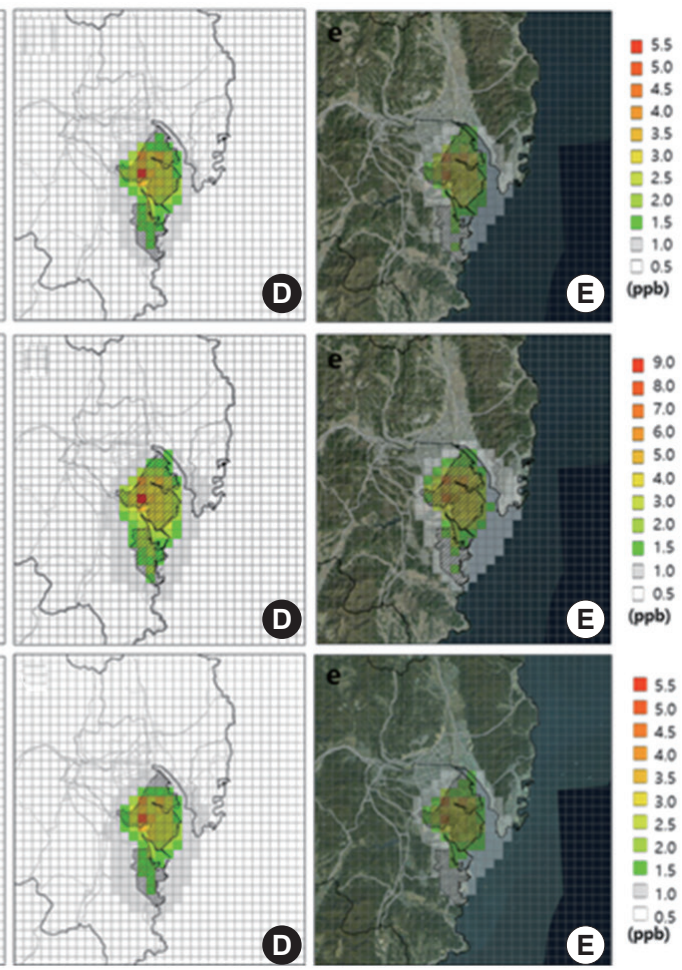

Figure 4. Horizontal distributions of differences in benzene, toluene and xylene concentrations between simulation A and B (A minus B). (A) January, (B) April, (C) July, (D) October, and (E) annual mean. ppb, parts per billion.

significantly higher than those of the SJ site, indicating that the influence of IC decreased significantly with distance. While smaller than that for the urban area, the contribution of the IC was calculated as 27 to $29 \%$. 
Table 1. Simulated annual mean BTX concentrations and contribution rates of industrial pollutant emissions to BTX levels in the selected urban area and at YC and SJ sites

\begin{tabular}{|c|c|c|c|c|c|}
\hline Pollutants & Area/site & Simulation A & $\begin{array}{l}\text { Difference between } \\
\text { simulations } A \text { and } B\end{array}$ & Contribution rate (\%) & Measurement \\
\hline Toluene & $\begin{array}{l}\text { Urban } \\
\text { YC } \\
\text { SJ }\end{array}$ & $\begin{array}{l}1.9 \pm 1.3 \\
4.8 \pm 2.6 \\
2.1 \pm 1.7\end{array}$ & $\begin{array}{l}1.0 \pm 1.1 \\
1.2 \pm 2.5 \\
1.0 \pm 1.5\end{array}$ & $\begin{array}{l}39.5 \pm 22.3 \\
84.5 \pm 8.7 \\
28.7 \pm 27.7\end{array}$ & $\begin{array}{l}- \\
8.1 \\
0.7\end{array}$ \\
\hline Xylene & $\begin{array}{l}\text { Urban } \\
\text { YC } \\
\text { SJ }\end{array}$ & $\begin{array}{l}1.0 \pm 0.7 \\
2.7 \pm 1.5 \\
1.1 \pm 0.9\end{array}$ & $\begin{array}{l}0.5 \pm 0.6 \\
2.4 \pm 1.4 \\
0.5 \pm 0.8\end{array}$ & $\begin{array}{l}40.3 \pm 22.4 \\
85.8 \pm 8.7 \\
29.0 \pm 27.9\end{array}$ & $\begin{array}{r}- \\
29.6 \\
0.2\end{array}$ \\
\hline Benzene & $\begin{array}{l}\text { Urban } \\
\text { YC } \\
\text { SJ }\end{array}$ & $\begin{array}{l}1.3 \pm 0.8 \\
2.9 \pm 1.5 \\
1.4 \pm 1.1\end{array}$ & $\begin{array}{l}0.6 \pm 0.7 \\
2.5 \pm 1.4 \\
0.6 \pm 0.6\end{array}$ & $\begin{array}{l}36.6 \pm 21.3 \\
82.1 \pm 8.8 \\
26.9 \pm 26.4\end{array}$ & $\begin{array}{c}- \\
2.9 \\
0.2\end{array}$ \\
\hline
\end{tabular}

Unit: parts per billion (ppb).

BTX, benzene, toluene, and xylene; YC, Yeocheon; SJ, Sinjeong.
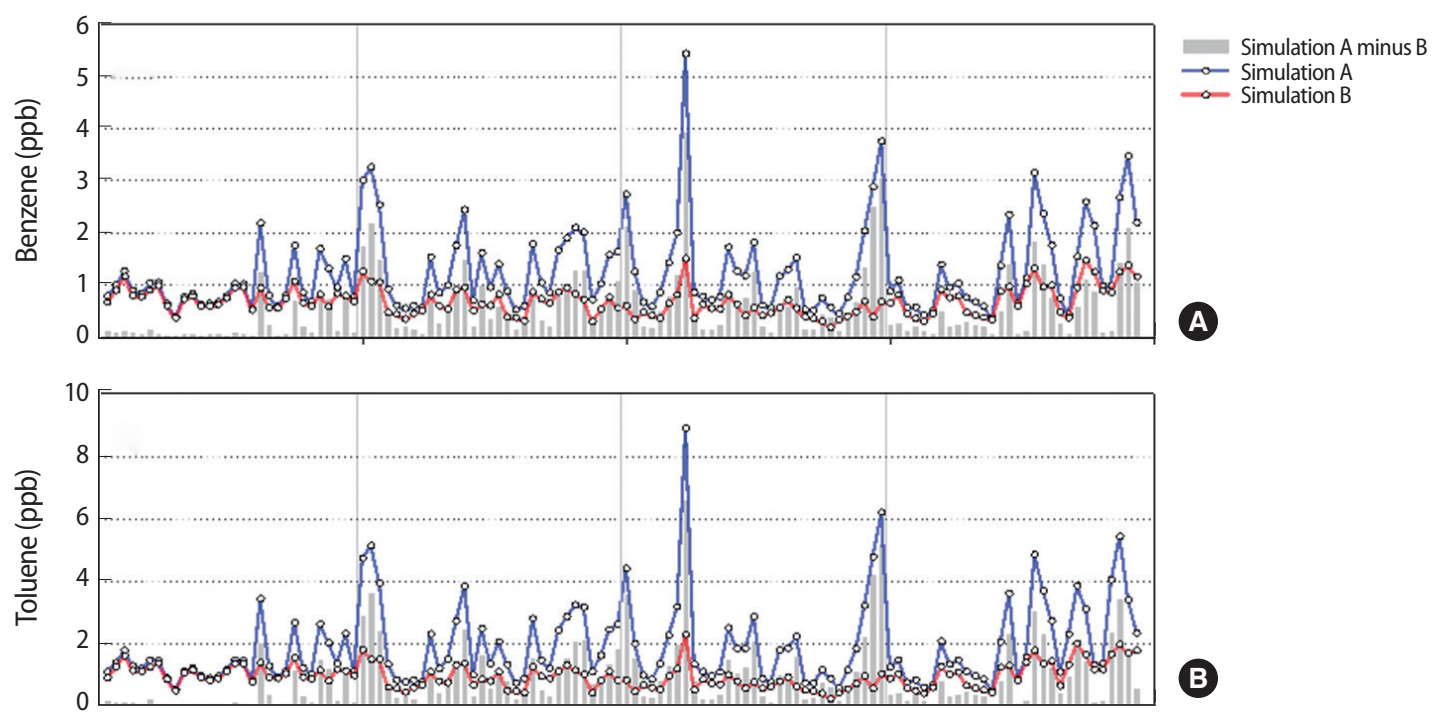

B

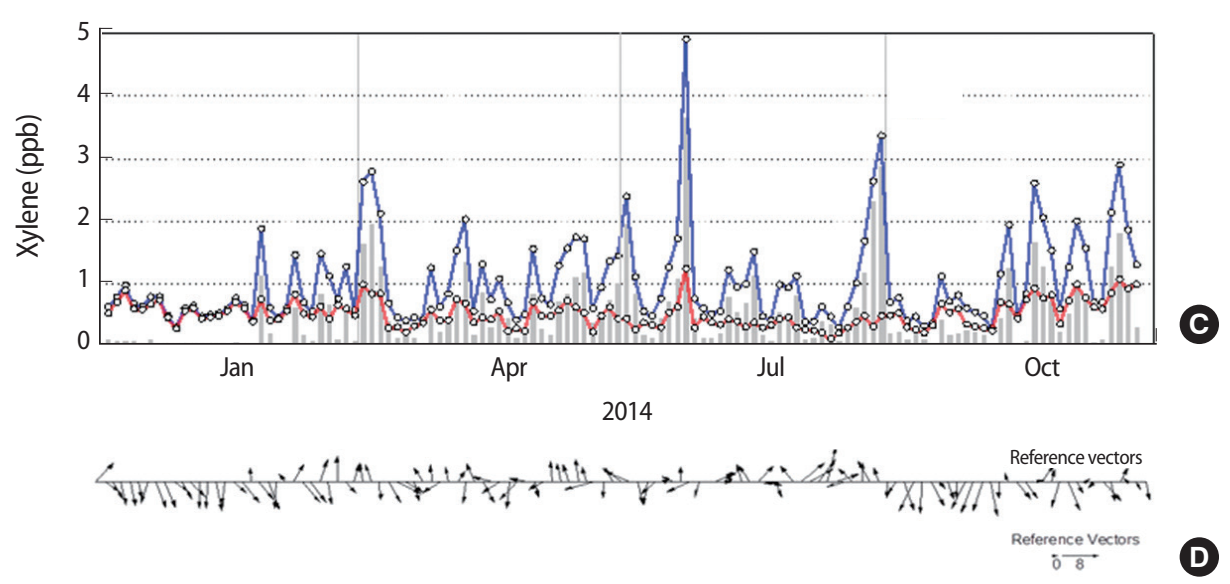

Figure 5. Daily variation of $(A)$ benzene, $(B)$ toluene, and $(C)$ xylene concentrations from simulation $A$ and $B$, and (D) area-mean 2 m wind vectors over the industrial complex. ppb, parts per billion.

Figure 5 shows the influence of IC on the changes in daily average BTX concentrations in urban vicinity grids. Overall, the contribution ranged from 4.9 to $86.7 \%$ for benzene, 4.6 to $87.9 \%$ for toluene, and 5.3 to $87.9 \%$ for xylene, with April and July contribution values being higher compared to those from
January and October. Moreover, changes in contributions depending on the wind conditions were observed (Figure 5D); when the wind blew towards the urban areas across the IC (south-southeasterly winds), it contributed to a rise in contributions in the same months. 


\section{DISCUSSION}

This study utilized high-resolution CMAQ modeling to identify the seasonal spatial distribution of BTX concentrations in the UMR and quantitatively evaluated the effects of pollutant emissions from IC on BTX concentrations in urban areas from emission control simulations. CMAQ simulation results indicated high average BTX concentrations in the IC and nearby areas, as well as differences in seasonal spatial distributions. The results of pollutant emissions control modeling showed the significant influence of IC on the BTX concentrations near the IC; this influence was largest (with seasonal variations) in the areas nearby petrochemical complexes. The results of contribution evaluations with the selected urban-area grids located near the IC indicated that approximately $40 \%$ of the concentrations were directly influenced by emissions from the IC. While all three compounds showed similar seasonal differences, their contributions were highest during July. In the daily contribution analysis, daily differences were large; July displayed values exceeding $85 \%$, showing a relationship with wind directions.

The modeling results clearly showed that high BTX concentrations in Ulsan were limited to certain areas close to the IC. This was because the fixed pollutant sources (petrochemical-related businesses) located within the IC had a large influence [27], and because BTX-related compounds were usually dealt with in these businesses [28]. Moreover, the pollutants emitted from the IC can be consumed through photochemical reactions or be diluted in the dispersion process, leading to a large local gradient of BTX concentration. Particularly, as BTX is an aromatic hydrocarbon, it has a high photochemical $\mathrm{O}_{3}$ creation potential $[29,30]$, and its concentrations may be reduced by mobile pollutant sources in the urban areas close to the IC.

This study was significant as it was the first to produce highresolution temporal and spatial information on a key HAP, $\mathrm{BTX}$, in the UMR, where major national industrial IC are located. Moreover, it has provided essential data to identify the influence and contribution of pollutant emissions from IC in the region. In particular, this study confirmed that the BTX concentration gradient in the region and changes associated with seasonal distribution are important, especially in relation to the assessment of exposure levels of urban residents. Accuracy of BTX exposure assessments for individuals could be improved through high-resolution spatial BTX concentrations reproduced by CMAQ modeling. Furthermore, improving the information through synthesis of numerical modeling results and measurement data could lead to better scientific assessments of individual exposure. The application of various exposure assessments using measurements, statistics, and numerical modeling could lead to different results for health impact assessments. According to recent research by Kim et al. [31], the relevance and influence of levels of air pollution to allergic symptoms may differ depending on methods used for assessing exposure. Therefore, when using numerical models to fill gaps in insufficient measured data, it is important to carefully consider spatial and temporal characteristics of concentrations, differences with actual concentrations, and expected uncertainties associated with the numerical model.

This study had the following limitations: Firstly, given that there were significant uncertainties regarding pollutant emissions, including VOCs, in CMAQ modeling, careful evaluation of industrial emission inventories was important. Secondly, the modeling conducted in this study demonstrated appropriate reproduction of $\mathrm{NO}_{2}$ and $\mathrm{O}_{3}$ levels; however, the measured data was insufficient to evaluate the simulated BTX concentrations. As the difference between average time periods of the measured and simulated concentrations was large, as presented in Figure 2, direct comparisons could not be made. Particularly, the model values at the $\mathrm{YC}$ site showed a clear trend of underestimating the measured values; this appeared to be a limitation in the calculation of gridded emissions from the IC. These results were similar to previous modeling studies $[32,33]$. There were clear differences with actual values given the uncertainty of emissions and limitations of the CMAQ model itself, which ultimately present limitations to the quantitative interpretation of the numerical simulation results. Thirdly, there were limitations in providing simple explanations of the direct influences of the IC. This was because pollutant emissions from other IC and related chemical reactions were not considered for emissions control modeling. Lastly, the values proposed in the analysis of contributions of the IC were calculated for the selected urban grids and at NHAM sites; this presented limitation in providing accurate explanations for the influence of specific areas near the IC and average influences from all regions. These limitations could be overcome through further studies that improve the model inputs, further emission sensitivity modeling studies, and an expansion of air pollutant monitoring near IC.

This study performed high-resolution analysis of the spatial distribution of BTX concentrations in an industrial city, and the quantitative evaluation of the influence of IC. Moreover, this study identified uncertainties associated with limitations in BTX modeling and its verification; these limitations could affect numerical modeling results on exposure assessment and health effect studies. However, the results of this study could be utilized in the management of hazardous air pollution in cities with large IC, and as data for improving the reliability of epidemiologic studies in evaluating the health impacts on nearby residents. 


\section{ACKNOWLEDGEMENTS}

This research was conducted with support from the National Institute of Environmental Research and the Environmental Health Center of the Ministry of Environment.

\section{CONFLICT OF INTEREST}

The authors have no conflicts of interest associated with material presented in this paper.

\section{ORCID}

Jin-Hee Bang https://orcid.org/0000-0003-3781-4334

Inbo Oh https://orcid.org/0000-0001-9545-2517

Soontae Kim https://orcid.org/0000-0002-1198-934X

Seunghee You https://orcid.org/0000-0001-9855-3356

Yangho Kim https://orcid.org/0000-0002-6462-0829

Ho-Jang Kwon https://orcid.org/0000-0003-3029-5674

Geun-Bae Kim https://orcid.org/0000-0001-8531-1104

\section{REFERENCES}

1. Choi CS. National standards of HAPs for industrial processes. Korean Ind Chem News 2016;19(1):3-11 (Korean).

2. Edokpolo B, Yu QJ, Connell D. Health risk assessment of ambient air concentrations of benzene, toluene and xylene (BTX) in service station environments. Int J Environ Res Public Health 2014;11(6): 6354-6374.

3. Baek SO, Jeon CG. Current status and future directions of management of hazardous air pollutants in Korea-focusing on ambient air monitoring issues. J Korean Soc Atmos Environ 2013;29(5):513527 (Korean).

4. Singla V, Pachauri T, Satsangi A, Kumari KM, Lakhani A. Comparison of BTX profiles and their mutagenicity assessment at two sites of Agra, India. Sci World J 2012;2012:272853,

5. Pollutant Release and Transfer Register. Pollutant release and transfer for each substance; 2014 [cited 2017 Jun 20]. Available from: http://icis.me.go.kr/prtr/prtrInfo/unitySearch.do (Korean).

6. Porstmann F, Böke J, Hartwig S, Kaaden R, Rosenlehner R, Schupp A, et al. Benzene and toluene in children's bedrooms. Staub Reinhaltung der Luft 1994;54(4):147-153 (German).

7. Ware JH, Spengler JD, Neas LM, Samet JM, Wagner GR, Coultas D, et al. Respiratory and irritant health effects of ambient volatile organic compounds. The Kanawha County Health Study. Am J Epidemiol 1993;137(12):1287-1301.

8. National Institute of Environmental Research. Annual report of air quality in Korea 2015 [cited 2017 Jun 20]. Available from: http:// webbook.me.go.kr/DLi-File/NIER/09/5618423.pdf (Korean).

9. Oh I, Bang JH, Kim S, Kim E, Hwang MK, Kim Y. Spatial distribution of air pollution in the Ulsan metropolitan region.J Korean Soc Atmos Environ 2016;32(4):394-407 (Korean).
10. Na KS, Kim YP, Moon KC. Comparison of the concentrations of ambient volatile organic compounds at an Ulsan industrial site in 1997 and 1998. J Korean Soc Atmos Environ 1999:15(5):567-574 (Korean).

11. Kim SJ, Kwon HO, Choi SD. Distribution of volatile organic compounds (VOCs) in Ulsan. In: Korean Society for Atmospheric Environment. Proceedings of the 57th Meeting of Korean Society for Atmospheric Environment; 2014 Oct 30-31; Pyeongchang. Seoul: Korean Society for Atmospheric Environment; 2014, p. 80 (Korean).

12. Korea Meteorological Administration. Climatological normals of Korea 1981-2010; 2011 [cited 2017 Jun 20]. Available from: http://www.kma.go.kr/down/Climatological_2010.pdf (Korean).

13. Oh I, Bang JH, Kim Y. Meteorological characteristics in the Ulsan metropolitan region: focus on air temperature and winds. J Korean Soc Atmos Environ 2015;31(2):181-194 (Korean).

14. National Institute of Environmental Research. Annual report of air quality in Korea 2013; 2014 [cited 2017 Jun 20]. Available from: http://webbook.me.go.kr/DLi-File/NIER/09/019/5584427.pdf (Korean).

15. Environmental Protection Agency. Science algorithms of the EPA models-3 community multiscale air quality (CMAQ) modeling system. Washington, DC: US Environmental Protection Agency; 1999, p.727.

16. Community Modeling and Analysis System. SMOKE v3.1 user's manual; 2012 [cited 2017 Jun 20]. Available from: https://www. cmascenter.org/smoke/documentation/3.1/manual_smokev31. pdf.

17. Community Modeling and Analysis System. CMAQ version 5.0 (February 2012 release) technical documentation [cited 2017 Jun 20]. Available from: https://www.airqualitymodeling.org/index. php/CMAQ version_5.0_(February_2012_release)_Technical_Documentation.

18. Reis S, Pinder RW, Zhang M, Lijie G, Sutton MA. Reactive nitrogen in atmospheric emission inventories. Atmos Chem Phys 2009; 9(19):7657-7677.

19. Community Modeling and Analysis System. UNC spatial allocator version 4.2; 2014 [cited 2017 Jun 20]. Available from: http://www. cmascenter.org/sa-tools/documentation/4.2/html/.

20. Cater WP. Documentation of the saprc- 99 chemical mechanism for VOC reactivity assessment; 1999 [cited 2017 Jun 20]. Available from: http://www.engr.ucr.edu/ carter/pubs/s99doc.pdf.

21. National Institute of Environmental Research. Studies on the optimization method for improving the accuracy of air quality modeling, Korea; 2014 [cited 2017 Jun 20]. Available from: http://webbook.me.go.kr/DLi-File/NIER/06/020/5567639.pdf (Korean).

22. Guenther CC. Estimates of global terrestrial isoprene emissions using MEGAN (model of emissions of gases and aerosols from nature). Atmos Chem Phys 2006;6:3181-3210.

23. Carmichael GR, Calori G, Hayami H, Uno I, Cho SY, Engardt M, et al. The MICS-Asia study: model intercomparison of long-range transport and sulfur deposition in East Asia. Atmos Environ 2002; 36(2):175-199.

24. Ministry of Environment. Installation and operating instruction of air pollutants measurement site; 2016 [cited 2017 Jun 20]. Avail- 
able from: http://www.me.go.kr/home/file/readDownloadFile. do?fileId=118729\&fileSeq=2 (Korean).

25. Baek SO, Kim SR, Kim BK. Variation of and affecting factors on the atmospheric concentrations of volatile organic compounds in an urban area. J Korean Soc Environ Eng 2002;24(8):1391-1404 (Korean).

26. Kim KH, Kim MY, Oh SI, Yun JS, Lee G. Studies of ambient BTEX distribution characteristics in the Nan-Ji-Do landfill site in Seoul. J Korean Soc Atmos Environ 2001;17(6):463-474 (Korean).

27. Gu MJ, Choi SW. Characteristics of source and concentration of VOCs in Daegu. J Environ Sci 2005; 14(6):543-553 (Korean)

28. Jeon JM, Hur D, Kim DS. Trend of volatile organic compounds in the ambient air of Yeosu industrial complex. J Korean Soc Atmos Environ 2003; 19(6):663-677 (Korean).

29. Cheong JP, You SJ. Estimation on the contribution of VOCs and nitric oxides in creating photochemical ozone. J Korean Soc Environ
Eng 2010;32(2):209-218 (Korean).

30. Derwent RG, Jenkin ME, Saunders SM. Photochemical ozone creation potentials for a large number of reactive hydrocarbons under European conditions. Atmos Environ 1996;30(2):181-199.

31. Kim YM, Kim J, Han Y, Lee BJ, Choi DC, Cheong HK, et al. Comparison of diverse estimation methods for personal exposure to air pollutants and associations with allergic symptoms: the Allergy \& Gene-Environment Link (ANGEL) study. Sci Total Environ 2017; 579:1127-1136.

32. Baker KR, Carlton AG, Kleindienst TE, Offenberg JH, Beaver MR, Gentner DR, et al. Gas and aerosol carbon in California: comparison of measurements and model predictions in Pasadena and Bakersfield. Atmos Chem Phys 2015;15(9):5243-5258.

33. Ramos CJ. Modeling of air toxics from urban and industrial sources within complex terrain. Pullman: Washington State University; 2008, p. 49-52. 
Table S1. Configuration of the CCTM (CMAQ chemical transport model) modeling ${ }^{\mathrm{a}}$

\begin{tabular}{ll}
\hline Configuration options & Selected modules \\
\hline Gas-phase chemistry mechanism & cb05_ae5_aq \\
Gas-phase chemistry solver & ebi_cb05 \\
Horizontal/vertical advection & hyamo/vwrf \\
Horizontal/vertical diffusion & multiscale/acm2 \\
Aerosol module & aero5 \\
Deposition velocity calculation & m3dry \\
Cloud module & cloud_acm_ae5
\end{tabular}

CCTM, Community Multiscale Air Quality Chemical Transport Model.

${ }^{\text {aF }}$ rom $\mathrm{Oh} \mathrm{I}$, et al. Meteorological characteristics in the Ulsan metropolitan region: focus on air temperature and winds. J Korean Soc Atmos Environ 2015;31(2): 181-194 (Korean). 
Environmental Health and Toxicology 2017;32:e2017022

Table S2. CMAQ performance statistics for hourly $\mathrm{PM}_{10}, \mathrm{NO}_{2}$, and $\mathrm{O}_{3}$ concentrations

\begin{tabular}{|c|c|c|c|c|}
\hline \multirow{2}{*}{ Statistical measures } & & \multicolumn{3}{|c|}{ Pollutants } \\
\hline & & $\mathrm{PM}_{10}\left(\mu \mathrm{g} / \mathrm{m}^{3}\right)$ & $\mathrm{NO}_{2}(\mathrm{ppb})$ & $0_{3}(\mathrm{ppb})$ \\
\hline Mean (AQMS/CMAQ) & $\begin{array}{l}\text { Jan } \\
\text { Apr } \\
\text { Jul } \\
\text { Oct }\end{array}$ & $\begin{array}{l}51.9 / 35.3 \\
54.3 / 21.3 \\
43.9 / 15.4 \\
39.1 / 21.3\end{array}$ & $\begin{array}{l}23.6 / 21.3 \\
29.9 / 23.9 \\
22.0 / 22.5 \\
21.2 / 21.1\end{array}$ & $\begin{array}{l}18.6 / 22.2 \\
33.4 / 35.9 \\
29.8 / 31.6 \\
24.2 / 28.1\end{array}$ \\
\hline r & $\begin{array}{l}\text { Jan } \\
\text { Apr } \\
\text { Jul } \\
\text { Oct }\end{array}$ & $\begin{array}{l}0.65 \\
0.43 \\
0.48 \\
0.52\end{array}$ & $\begin{array}{l}0.68 \\
0.66 \\
0.47 \\
0.64\end{array}$ & $\begin{array}{l}0.67 \\
0.65 \\
0.6 \\
0.62\end{array}$ \\
\hline $\mathrm{MB}$ & $\begin{array}{l}\text { Jan } \\
\text { Apr } \\
\text { Jul } \\
\text { Oct }\end{array}$ & $\begin{array}{l}-17.7 \\
-39.4 \\
-28.2 \\
-18.5\end{array}$ & $\begin{array}{r}-1.5 \\
-3.6 \\
3.2 \\
-5.5\end{array}$ & $\begin{array}{l}1.4 \\
0.1 \\
2.4 \\
2.1\end{array}$ \\
\hline NMB (\%) & $\begin{array}{l}\text { Jan } \\
\text { Apr } \\
\text { Jul } \\
\text { Oct }\end{array}$ & $\begin{array}{l}-30.7 \\
-66.4 \\
-65.9 \\
-46.5\end{array}$ & $\begin{array}{r}-6.6 \\
-13.6 \\
14.8 \\
-21.3\end{array}$ & $\begin{array}{l}7.7 \\
0.9 \\
9.2 \\
8.6\end{array}$ \\
\hline NME (\%) & $\begin{array}{l}\text { Jan } \\
\text { Apr } \\
\text { Jul } \\
\text { Oct }\end{array}$ & $\begin{array}{l}40.7 \\
68.4 \\
73.7 \\
54.3\end{array}$ & $\begin{array}{l}27.1 \\
35.1 \\
43.5 \\
33.2\end{array}$ & $\begin{array}{l}41.1 \\
38.8 \\
46.2 \\
45.3\end{array}$ \\
\hline RMSE & $\begin{array}{l}\text { Jan } \\
\text { Apr } \\
\text { Jul } \\
\text { Oct }\end{array}$ & $\begin{array}{l}30.5 \\
49.3 \\
36.9 \\
25.3\end{array}$ & $\begin{array}{r}9.5 \\
14.7 \\
16.1 \\
13.6\end{array}$ & $\begin{array}{l}10.5 \\
17.7 \\
16.5 \\
14.3\end{array}$ \\
\hline $10 \mathrm{~A}$ & $\begin{array}{l}\text { Jan } \\
\text { Apr } \\
\text { Jul } \\
\text { Oct }\end{array}$ & $\begin{array}{l}0.68 \\
0.50 \\
0.58 \\
0.65\end{array}$ & $\begin{array}{l}0.80 \\
0.79 \\
0.72 \\
0.76\end{array}$ & $\begin{array}{l}0.81 \\
0.80 \\
0.79 \\
0.74\end{array}$ \\
\hline
\end{tabular}

CMAQ, Community Multiscale Air Quality; AQMS, air quality monitoring sites; ppb, parts per billion; $\mathrm{PM}_{10}$, aerodynamic diameter $<10 \mu \mathrm{m}$; $\mathrm{NO}_{2}$, nitrogen dioxide $\mathrm{O}_{3}$, ozone; r: Pearson's correlation coefficient; MB: mean bias; NMB: mean normalized bias; NME: mean normalized error; RMSE: root mean square error; IOA: index of agreement. 